University of Nebraska - Lincoln

DigitalCommons@University of Nebraska - Lincoln

Publications from USDA-ARS / UNL Faculty

U.S. Department of Agriculture: Agricultural

Research Service, Lincoln, Nebraska

2013

\title{
TsDAF-21/Hsp90 is expressed in all examined stages of Trichinella spiralis
}

\author{
Yurong Yang \\ Xiamen University, yryang@xmu.edu.cn \\ Weiwen Qin \\ Xiamen University \\ Dante Zarlenga \\ ARS, Animal Parasitic Diseases Laboratory \\ Lei Cao \\ Xiamen University \\ Guimei Tian \\ Xiamen University
}

Follow this and additional works at: https://digitalcommons.unl.edu/usdaarsfacpub

Yang, Yurong; Qin, Weiwen; Zarlenga, Dante; Cao, Lei; and Tian, Guimei, "TsDAF-21/Hsp90 is expressed in all examined stages of Trichinella spiralis" (2013). Publications from USDA-ARS / UNL Faculty. 2267.

https://digitalcommons.unl.edu/usdaarsfacpub/2267

This Article is brought to you for free and open access by the U.S. Department of Agriculture: Agricultural Research Service, Lincoln, Nebraska at DigitalCommons@University of Nebraska - Lincoln. It has been accepted for inclusion in Publications from USDA-ARS / UNL Faculty by an authorized administrator of DigitalCommons@University of Nebraska - Lincoln. 


\title{
TsDAF-21/Hsp90 is expressed in all examined stages of Trichinella spiralis
}

\author{
Yurong Yang ${ }^{\mathrm{a}, *}$, Weiwen Qin $^{\mathrm{a}}$, Dante Zarlenga ${ }^{\mathrm{b}}$, Lei Cao ${ }^{\mathrm{a}}$, Guimei Tian ${ }^{\mathrm{a}}$ \\ a State Key Laboratory of Cellular Stress Biology, School of Life Science, Xiamen University, Xiamen, Fujian 361005, People's Republic of \\ China \\ b ARS, Animal Parasitic Diseases Laboratory, Beltsville, MD 20705, USA
}

\section{A R T I C L E I N F O}

\section{Keywords:}

Trichinella spiralis

Tsdaf-21/Hsp90

Heat shock proteins

Phylogenetic analysis

\begin{abstract}
A B S T R A C T
Trichinella is an important parasitic nematode of animals worldwide. Heat shock proteins are ubiquitous in nature and allow organisms to quickly respond to environmental stress. A portion of the Tsdaf-21 gene, a Caenorhabditis elegans daf-21 homologue encoding heat-shock protein 90 (Hsp90) was cloned from Trichinella spiralis. The partial nucleotide sequence resided near the $5^{\prime}$-end of the gene and encoded a polypeptide of 254 amino acid residues harboring a HATPase-c superfamily domain and Hsp90 protein domain. Phylogenetic analysis revealed that Tsdaf-21 is highly conserved and formed a monophyletic clade with other nematodes. The partial Tsdaf-21 transcript was subcloned and expressed for antibody production. Results using PCR primers specific for the Tsdaf-21 transcript, and mouse polyclonal antisera specific for the recombinant protein showed that both the RNA transcript and the corresponding protein were ubiquitously and consistently expressed in newborn larvae, muscle larvae and both male and female adult worms in the absence of any external stress or stimulation.
\end{abstract}

(C) 2013 Elsevier B.V. All rights reserved.

\section{Introduction}

Trichinella is an important and global zoonotic parasite. Organisms belonging to this genus infect a wide variety of animals including humans. Infection is caused by ingesting meat contaminated with encysted muscle larvae (ML). The ML can remain viable within the host tissue for long periods of time even when stored at low temperatures $\left(4^{\circ} \mathrm{C}\right.$ in refrigerator).

Heat shock proteins (Hsp) function as molecular chaperones and are involved in many cellular processes including protein trafficking, signal transduction, differentiation and development (Devaney, 2006). They play key roles in

\footnotetext{
* Corresponding author at: Parasite Research Lab, Department of Biology, School of Life Science, Xiamen University, Xiamen, Fujian 361005, People's Republic of China. Tel.: +86 592 2181792; fax: +86 5922180038. E-mail address: yryang@xmu.edu.cn (Y. Yang).
}

stress response, help denatured proteins to refold, prevent protein aggregation, and assist in targeting protein degradation by proteasomes and lysosomes (Saunders and Verdin, 2009). This family of proteins also plays a role in apoptosis and helps modulate signals involved in the immune system and the inflammatory response (Shiny et al., 2011). Heat shock proteins are classified according to their molecular weights and grouped into many families, such as small Hsps, Hsp60, Hsp70 and Hsp90. It is now recognized that most of these proteins are induced in response to a wide variety of stresses, such as low or high temperatures, heavy metal exposure or parasite infection.

Heat shock proteins 60, 70 and 90 have been found in Trichinella nativa, Trichinella nelsoni, Trichinella pseudospiralis and Trichinella spiralis after larval exposure to hydrogen peroxide $\left(\mathrm{H}_{2} \mathrm{O}_{2}\right)$ (Martinez et al., 2002a). Specifically, Hsp60 and Hsp70, but not Hsp90 were constitutively phosphorylated at their serine/threonine residues (Martinez et al., 2002a). Furthermore, the induction of 
constitutive and higher molecular weight Hsp correlated strongly with the loss of larval viability and an increase in mortality following exposure to $\mathrm{H}_{2} \mathrm{O}_{2}$ (Martinez et al., 1999). After $\mathrm{H}_{2} \mathrm{O}_{2}$ shock, both $\mathrm{Hsp} 90$ and a $50 \mathrm{kDa} \mathrm{Hsp}$ (prot-50) were significantly elevated, whereas only Hsp90 levels decreased after cold shock (Martinez et al., 2002b). It was also found that $T$. spiralis ML stored in 199 medium at $37^{\circ} \mathrm{C}$ lost infectivity and this coincided with a concomitant reduction in Hsp70 and Hsp90. An inducible Hsp, Hsp90i, appeared as the expression of the more constitutive Hsp90 decreased in stored larvae (Martinez et al., 2004).

In Caenorhabditis elegans, daf-21 encodes an Hsp90 that is primarily expressed in germline cells. After heat stress, daf-21 is expressed throughout the entire body of the worm (Inoue et al., 2003). Furthermore, daf-21 was found involved in egg hatching and motility; however, mutations to the daf-21 gene had deleterious effects on animal fertility and induced early larval lethality. The daf-21 protein indirectly regulates the meiotic prophase/metaphase transition during oocyte development by ensuring the normal function of WEE-1.3 (Inoue et al., 2006). In contrast, daf21 mutants show multiple chemosensory defects in taxis to volatile and non-volatile attractants, and inappropriate responses to the dauer-inducing pheromone (Birnby et al., 2000). Except in response to stress, other functions of Hsp90 in Trichinella spp. remain unclear. In this paper, we report both gene and protein expression profiles of Hsp90 in different stages of $T$. spiralis.

\section{Materials and methods}

\subsection{Parasites and experimental infection}

T. spiralis (ISS 534) was maintained by serial passage in mice. Muscle larvae were isolated 30 days post infection (p.i.) from skeletal muscle by overnight digestion in 1\% pepsin: $3.6 \% \mathrm{HCl}$ at $37^{\circ} \mathrm{C}$. To obtain adult worms from the intestine, mice infected with $T$. spiralis ML, were euthanized 6 days post infection. Newborn larvae (NBL) were collected from female adult worms incubated for $24 \mathrm{~h}$ in RPMI 1640 medium (GIBCO). All worm preparations were washed several times with physiological saline before DNA or RNA extraction.

\subsection{RNA extraction and $C D N A$ cloning}

Total RNA was prepared from NBL, ML, and male and female adult worms using Trizol (MRC) according to the manufacturer; cDNA was synthesized using the 3'-Full RACE Core set kit (Takara Biotechnology Co. Ltd., Dalian). The resulting cDNA was used to amplify $T$. spiralis daf-21 cDNA by polymerase chain reaction (PCR) in a total volume of $50 \mu \mathrm{L}$ containing $1 \mu \mathrm{L}$ RT reaction, $2 \mu \mathrm{L}$ 3'RACE Outer Primer, $7 \mu \mathrm{L} 1 \times$ cDNA dilution buffer II, $2 \mu \mathrm{L}$ of Tsdaf21F primer ( $5^{\prime}$-CCCACGCGTCCGCGTTGTTTGTGCT; derived from the $5^{\prime}$ end of EST sequence ES566819), $5 \mu \mathrm{L}$ $10 \times$ ExTaq buffer, $0.25 \mu \mathrm{L}$ ExTaq polymerase, and $30.75 \mu \mathrm{L}$ $\mathrm{ddH}_{2} \mathrm{O}$. The PCR was performed as follows: $94^{\circ} \mathrm{C}$ for $3 \mathrm{~min}$ followed by 36 cycles of $30 \mathrm{~s}$ at $94^{\circ} \mathrm{C}, 30 \mathrm{~s}$ at $53.5^{\circ} \mathrm{C}$, $1 \mathrm{~min}$ at $72^{\circ} \mathrm{C}$; a final extension was performed at $72^{\circ} \mathrm{C}$ for $10 \mathrm{~min}$. The PCR product was gel purified, cloned into
pMD18 T and used to transform Escherichia coli Dh5 $\alpha$ cells. Positive colonies were identified by PCR and sequenced. One sequence was subcloned into the expression vector pET32 M (Invitrogen). The recombinant protein (rTsDAF21 ) was purified from $E$. coli BL21 (DE3) cells using Ni-NTA agarose (QIAGEN, Valencia, CA) according to the manufacturer's protocol. Antiserum was obtained by injecting mice intraperitoneally with $100 \mu \mathrm{g}$ of recombinant protein, mixed with Freund's complete adjuvant (Sigma, St. Louis, MO). The animals were boosted three times with $100 \mu \mathrm{g}$ protein in Freund's incomplete adjuvant and blood was collected 5 weeks later.

\subsection{Sequence and phylogenetic analysis}

Sequences were analyzed using NCBI utilities and BLAST searches (http://www.ncbi.nlm.nih.gov/BLAST). The putative amino acid sequence was identified using the ORF Finder program from the NCBI (http://www.ncbi.nlm.nih.gov/gorf/gorf.html). Amino acid sequences derived from the Tsdaf-21 were deposited into GenBank (Accession No. JN836431). For tree reconstruction, the predicted full-length amino acid sequence derived from the T. spiralis genome (XM_003374508) (Mitreva et al., 2011) minus the $3^{\prime}$ terminal 46 amino acids was aligned using Clustal W (Thompson et al., 1994) with those from C. elegans (NP_506626.1), Drosophila melanogaster (NP_523899.1), Xenopus laevis (NP_001086624.1), Mus musculus (NP_034610.1), Rattus norvegicus (NP_786937.1), Homo sapiens (NP_031381.2), Danio rerio (AAC21566.1), Taeniopygia guttata (XP_002200608.1), Ascaris suum (ACO55134.1), Toxocara cati (ACO55135.1), Liriomyza sativae (AAW49253.2), Tigriopus japonicus (ACA03524.1), Heterodera glycines (ACR57215.1), Haemonchus contortus (ACU00668.1) and Brugia pahangi (061998.2). Phylogenetic analyses were inferred using the Neighbor-Joining program in MEGA4 (Tamura et al., 2007). The evolutionary distances were computed using the Poisson correction where gaps and missing data were eliminated from the dataset; 684 amino acid positions were included in the final dataset.

\subsection{RT-PCR and protein analyses of Tsdaf-21}

Transcription levels of Tsdaf-21 were measured using oligo (dT) primed cDNA $(0.5 \mu \mathrm{L})$ synthesized from NBL, ML and adult worms using superscript II reverse transcriptase (Invitrogen). Amplification of Tsdaf-21 was performed using primers Thsp90F (5'-CTACATGGTGGATGCCATTG) and Thsp90R (5'-ACACGCTCGTACAACTGCTG) which generate a $393 \mathrm{bp}$ fragment that resides nearer the $3^{\prime}$ terminus of the sequence. The $\beta$-actin control was amplified using forward (ActF: 5'-CGTGGTTACTCTTTCCCGCTG) and reverse (ActR: $5^{\prime}$-CATTTAGAAGCACTTGCGGTGAACGATGG) primers. Reactions were cycled $25-40$ times $\left(94^{\circ} \mathrm{C} 30 \mathrm{~s}\right.$, $53.5^{\circ} \mathrm{C} 30 \mathrm{~s}, 72^{\circ} \mathrm{C} 1 \mathrm{~min}$ ) followed by a $72{ }^{\circ} \mathrm{C}, 8 \mathrm{~min}$ soak. Control samples without cDNA were included with each PCR run. Amplified products were separated on a $1 \%(\mathrm{w} / \mathrm{v})$ agarose gel, stained with ethidium bromide, and photographed under UV light. 


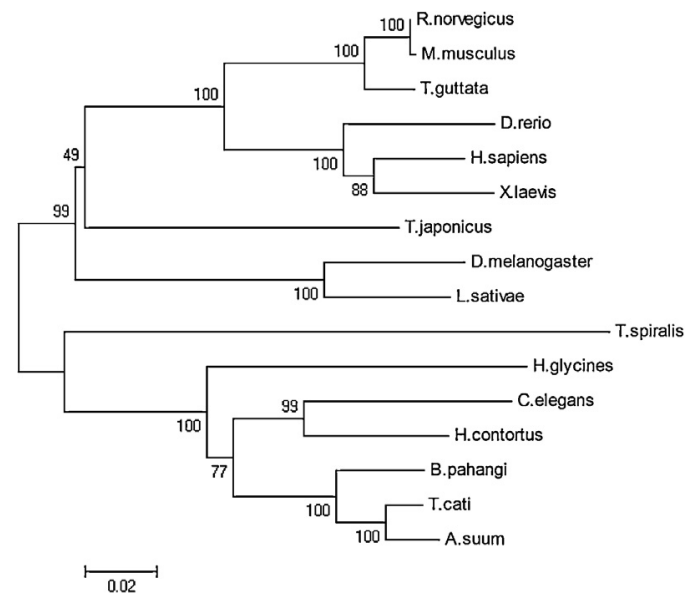

Fig. 1. Phylogenetic tree (N-J) of DAF-21/Hsp90 proteins from 16 species representing vertebrates, insects and nematodes. Evolutionary history was inferred using the N-J method within MEGA4 (Tamura et al., 2007). The evolutionary distances were computed using a Poisson correction for the number of amino acid substitutions per site. The optimal tree with the sum of branch length $=1.00969711$ is shown. Support numbers (bootstrap test; 1000 replicates) for each branch are also shown. Gaps and missing data were not considered in the final dataset which consisted of 684 positions.

For Western blots, worms were homogenized in phosphate buffered saline then centrifuged to remove debris. The protein content was determined using the Bradford assay (Biorad). Worm lysates were separated on $12 \%$ SDSPAGE gels, transferred to nitrocellulose, screened using rTsDAF-21 polyclonal mouse anti-sera (1:500 dilution) then visualized using the ECL Western blotting system (Biorad) according to the manufacturer's recommendations. Mouse anti- $\beta$-tubulin (1:500 dilution) was used as a control screen to normalize protein loading.

\section{Results and discussion}

\subsection{Sequence and phylogenetic analyses of Tsdaf-21}

The ML-derived Tsdaf-21 cDNA generated an ORF encoded a predicted protein of 254 amino acids. The sequence contained HATPase $\mathrm{c}$ and Hsp90 domains (JN836431). It should be noted that the 3' RACE primer did not bind as anticipated to the poly $A$ tail of the gene, but to an $A$ rich region approximately $850 \mathrm{bp}$ downstream of the translation start site. However, upon BLAST analysis, the partial sequence of Tsdaf-21 cloned herein demonstrated significant identity with sequences from a range of organisms, including plant parasitic nematodes, insects and vertebrates. Phylogenetic analysis using the near full-length TsDAF-21 protein sequence (XM_003374508) derived from genomic data (Mitreva et al., 2011) displayed high similarity with 15 other known Hsp90 proteins where the conserved Hsp90 domain region was most highly conserved (data not shown). These Hsp90 proteins basically formed 2 clades (Fig. 1). Into one clade fell higher eukaryotes (human, mouse and frog) and insects (fruit fly and fly) whereas the Hsp90 from all nematodes formed a separate and monophyletic clade. The Tsdaf-21 protein sequence

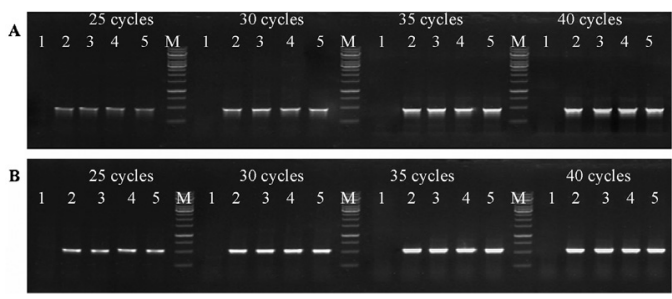

Fig. 2. Transcripts of the Tsdaf-21 in different stages of $T$. spiralis detected by RT-PCR (A) compared with an internal $\beta$-actin control (B). (1) Negative control; (2) NBL; (3) ML; (4) female adult worms; (5) male adult worms; $\mathrm{M}=$ molecular weight standards.

predictably positioned within the clade comprised of other nematodes and consistent with a lineage that diverged early in the evolution of the phylum Nematoda (Zarlenga et al., 2009). All nodes were well supported except for the single Hsp90 from T. japonicus, a marine gastropod invertebrate.

There are multiple T. spiralis Hsp90 submissions in GenBank derived from genes (2), mRNAs (5), proteins (5) and EST sequences (2). One sequence, XM_003374508, was predicted from sequencing the $T$. spiralis genome (Mitreva et al., 2011). Alignment provided information that the integrity of the $3^{\prime}$-terminus is suspect. As such, 46 amino acids of this putative full-length sequence were deleted prior to tree building. All additional sequences were overlapping; two are identical (XM003374508, EFV55915.1) and two EST sequences (ES570731 and ES562424) are incomplete but align well with Tsdaf-21. One sequence (XP003368967.1) was found to be quite different; however, upon additional analyses this sequence conforms more to Hsp75 than to Hsp90.

\subsection{Expression of Tsdaf-21 in developmental stages of $T$. spiralis}

The transcript of Tsdaf-21 was detected by RT-PCR in all stages of $T$. spiralis. A specific band of 393 bp was amplified from NBL, ML, and adult male and female worms (Fig. 2). The results suggest that Tsdaf-21 (Fig. 2A) is abundantly and consistently expressed in all stages and in both sexes of adult worms when referenced to actin as an internalcontrol

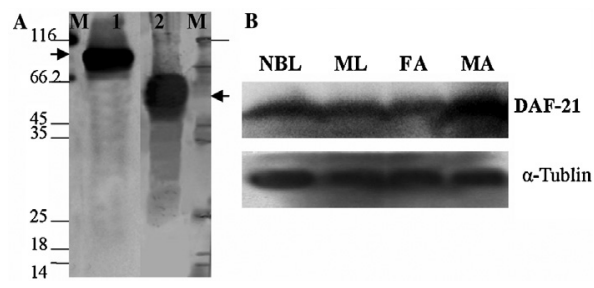

Fig. 3. Protein expression in different stages of $T$. spiralis detected by Western blot. (A) Native TsDAF-21 (lane 1) in ML crude worm extract and rTsDAF-21 (lane 2) were detected using mouse anti-rTsdaf-21 serum; $M$, pre-stained molecular weight markers. (B) Protein expression of TsDAF21 in new born larvae (NBL), muscle larvae (ML), female adult worms (FA) and male adult worms (MA) of $T$. spiralis detected using anti-rTsDAF-21 serum (1:500 dilution; upper panel). Tubulin was used to normalize protein loading and was detected with mouse anti- $\beta$-tubulin serum (1:500 dilution; lower panel). 
(Fig. 2B). Similar conclusions were drawn using mouse anti-rTsDAF-21 serum to screen crude worm extracts in Western blots. Data showed that the native TsDAF-21 was approximately $90 \mathrm{kDa}$ in size and equally expressed in all three stages examined including male and female adult worms (Fig. 3).

In conclusion, our data suggest that the Tsdaf-21 and the corresponding protein are ubiquitously and strongly expressed in all stages of Trichinella in the absence of external stress; however, the function of the protein, its regulation in response to external stress, and its role if any, in the infection process have yet to be investigated.

\section{Conflict of interest}

No financial or personal relationships are maintained with other people or organizations that could inappropriately influence or bias this paper.

\section{Acknowledgements}

This work was supported in part by funding from the Natural Science Foundation of China (No. 30972181) and a grant from Xiamen Science Technology program (3502Z20061098).

\section{References}

Birnby, D.A., Link, E.M., Vowels, J.J., Tian, H., Colacurcio, P.L., Thomas, J.H., 2000. A transmembrane guanylyl cyclase (DAF-11) and Hsp90 (DAF-21) regulate a common set of chemosensory behaviors in Caenorhabditis elegans. Genetics 155, 85-104.

Devaney, E., 2006. Thermoregulation in the life cycle of nematodes. Int. J. Parasitol. 36, 641-649.

Inoue, T., Hirata, K., Kuwana, Y., Fujita, M., Miwa, J., Roy, R., Yamaguchi, Y., 2006. Cell cycle control by daf-21/Hsp90 at the first meiotic prophase/metaphase boundary during oogenesis in Caenorhabditis elegans. Dev. Growth Differ. 48, 25-32.

Inoue, T., Takamura, K., Yamae, H., Ise, N., Kawakami, M., Tabuse, Y., Miwa, J., Yamaguchi, Y., 2003. Caenorhabditis elegans DAF21 (HSP90) is characteristically and predominantly expressed in germline cells: spatial and temporal analysis. Dev. Growth Differ. 45, 369-376.

Martinez, J., Perez-Serrano, J., Bernadina, W.E., Rincon, I., RodriguezCaabeiro, F., 2004. Heat shock protein synthesis over time in infective Trichinella spiralis larvae raised in suboptimal culture conditions. J. Helminthol. 78, 243-247.

Martinez, J., Perez-Serrano, J., Bernadina, W.E., Rodriguez-Caabeiro, F., 1999. In vitro stress response to elevated temperature, hydrogen peroxide and mebendazole in Trichinella spiralis muscle larvae. Int. J. Parasitol. 29, 1457-1464.

Martinez, J., Perez-Serrano, J., Bernadina, W.E., Rodriguez-Caabeiro, F., 2002a. Expression of Hsp90, Hsp70 and Hsp60 in Trichinella species exposed to oxidative shock. J. Helminthol. 76, 217-223.

Martinez, J., Perez-Serrano, J., Bernadina, W.E., Rodriguez-Caabeiro, F., 2002 b. Oxidative and cold shock cause enhanced induction of a $50 \mathrm{kDa}$ stress protein in Trichinella spiralis. Parasitol. Res. 88, 427-430.

Mitreva, M., Jasmer, D.P., Zarlenga, D.S., Wang, Z., Abubucker, S., Martin, J., Taylor, C.M., Yin, Y., Fulton, L., Minx, P., Yang, S.P., Warren, W.C., Fulton, R.S., Bhonagiri, V., Zhang, X., Hallsworth-Pepin, K., Clifton, S.W., McCarter, J.P., Appleton, J., Mardis, E.R., Wilson, R.K., 2011. The draft genome of the parasitic nematode Trichinella spiralis. Nat. Genet. 43, 228-235.

Saunders, L.R., Verdin, E., 2009. Cell biology, stress response and aging. Science 323, 1021-1022.

Shiny, C., Krushna, N.S., Babu, S., Elango, S., Manokaran, G., Narayanan, R.B. 2011. Recombinant Wolbachia heat shock protein 60 (HSP60) mediated immune responses in patients with lymphatic filariasis. Microbes Infect. 13, 1221-1231.

Tamura, K., Dudley, J., Nei, M., Kumar S, 2007. MEGA4: molecular evolutionary genetics analysis (MEGA) software version 4.0. Mol. Biol. Evol. 24, 1596-1599.

Thompson, J.D., Higgins, D.G., Gibson, T.J., 1994. CLUSTAL W: improving the sensitivity of progressive multiple sequence alignment through sequence weighting, position-specific gap penalties and weight matrix choice. Nucleic Acids Res 22, 4673-4680.

Zarlenga, D.S., Rosenthal, B., Hoberg, E., Mitreva, M., 2009. Integrating genomics and phylogenetics in understanding the history of Trichinella species. Vet. Parasitol. 159, 210-213. 